\title{
A Novel Friedel-Crafts Acylation Reaction of Anisole for Production of 4-Methoxyacetophenone with High Selectivity and Sufficient Reusability of Mordenite Zeolite Catalyst
}

\author{
Makoto Makihara, Kenichi Komura* \\ Department of Materials Science and Technology, Faculty of Engineering, Gifu University, Gifu, Japan \\ Email: ^kkomura@gifu-u.ac.jp
}

How to cite this paper: Makihara, M. and Komura, K. (2017) A Novel Friedel-Crafts Acylation Reaction of Anisole for Production of 4-Methoxyacetophenone with High Selectivity and Sufficient Reusability of Mordenite Zeolite Catalyst. Green and Sustainable Chemistry, 7, 185-192. https://doi.org/10.4236/gsc.2017.73014

Received: June 30, 2017

Accepted: July 17, 2017

Published: July 20, 2017

Copyright $\odot 2017$ by authors and Scientific Research Publishing Inc. This work is licensed under the Creative Commons Attribution International License (CC BY 4.0).

http://creativecommons.org/licenses/by/4.0/

\begin{abstract}
Zeolite catalyzed Friedel-Crafts reactions were examined using acetic anhydride as an acetylating agent and an acetic acid as a solvent. It revealed that the reaction of anisole smoothly occurred quantitatively for $3 \mathrm{~h}$ using mordenite zeolite with $\mathrm{SiO}_{2} / \mathrm{Al}_{2} \mathrm{O}_{3}=200$, and with $\mathrm{SiO}_{2} / \mathrm{Al}_{2} \mathrm{O}_{3}=110$, the increasing of Brønsted acidity allowed to completely react within $2 \mathrm{~h}$. Furthermore the selectivity of 4-methoxyacetophenone (4-MA) among the isomers was found to be quantitative, no by-products and/or isomers were not detectable. With the excellent recyclability and reusability, the mordenite zeolite exhibited at least 30 times quantitatively both conversion of anisole and selectivity of 4-MA. The mordenite catalysts of fresh and the used after 30 times were characterized. This opportunity obviously indicates the sufficient shape selective catalyst of mordenite zeolite and gives a green synthetic tool for heterogeneous acylation reaction.
\end{abstract}

\section{Keywords}

Zeolite, Friedel-Crafts, Acylation, Mordenite, Shape Selectivity

\section{Introduction}

Friedel-Crafts acylation reaction is one of the most useful synthetic tools in organic synthesis, because it allows it to be possible for introducing of important moieties such as acetyl and alkyl groups into aromatic compounds. In general textbook of organic chemistry, this reaction can be promoted by Lewis acid catalysts such as $\mathrm{AlCl}_{3}, \mathrm{HF}$ and $\mathrm{BF}_{3}$ using acid chlorides and alkylhalides for pro- 
ducing corresponding substituted aromatics. Unfortunately these conventional reactions produce large amounts of waste after the reaction by work-up, neutralization of catalyst and/or used reagent. Thus necessity of alternating to conventional catalytic reaction and a wide spreading concern for environmental benignity have triggered the development of economic and green chemical processes for Friedel-Crafts reaction. In researches of eco-friendly Friedel-Crafts acylations of anisole, usage of zeolite has been widely developed as promising catalysts as well as the index of shape selectivity of the zeolite due to their validities of three dimensional pore structure, so far [1] [2] [3]. Among the examined zeolite catalysts, reports on using BEA zeolites have been paid much attention, for example, using toluene as solvent [4] [5], neat conditions [6] [7] [8] and fixedbed vapor phase reaction [9]. Other approaches have been also examined by using mesoporous catalysts [2], MWW zeolitic material using nitrobenzene [10], ZSM-5 zeolite [11], ion-exchanged Y zeolite [12] [13], clays [14] and resin composite silica catalysts [15] [16] [17].

Recently we have successfully developed the highly selective Friedel-Crafts acylation of 2-methoxynaphthalene (2-MN) to obtain 2-methoxy-6-acetyl-naphthalene (2,6-ACMN) by MOR-type zeolite catalyst using acetic anhydride $\left(\mathrm{Ac}_{2} \mathrm{O}\right)$ as an acylating agent in acetic acid $(\mathrm{AcOH})$ as a solvent, and this reaction system is to be the highest conversion of 2-MN and the selectivity of 2,6-ACMN comparing with ever reported researches [18]. However the reusability of mordenite catalyst was found to be poor due to leaching of $\mathrm{Al}$ or heavy coke formation onto the acid site during the reaction, and it is marked that the reaction smoothly occurred using low acid amount of mordenite zeolite with $\mathrm{SiO}_{2} / \mathrm{Al}_{2} \mathrm{O}_{3}=200$ (designated as MOR(200)), whereas usage higher acid amount of mordenite catalyst caused low conversion of $2-\mathrm{MN}$, offering quite unique specific character of this reaction system. Friedel-Crafts reactions of anisole and some substrates which can be producing key intermediates by mordenite catalyst under our developed system are not clarified yet, therefore, in this report, we wish to disclose the excellent catalytic performance and the shape selectivity of mordenite zeolite, especially using anisole, as illustrated in Figure 1.

\section{Experiment}

\subsection{Characterization and Materials}

Powder X-ray diffraction (XRD) was measured by a Shimadzu XRD-6000 diffractometer with $\mathrm{CuKa}$ radiation $(\lambda=1.5418 \AA$ ) $)$. Elemental analyses were per-

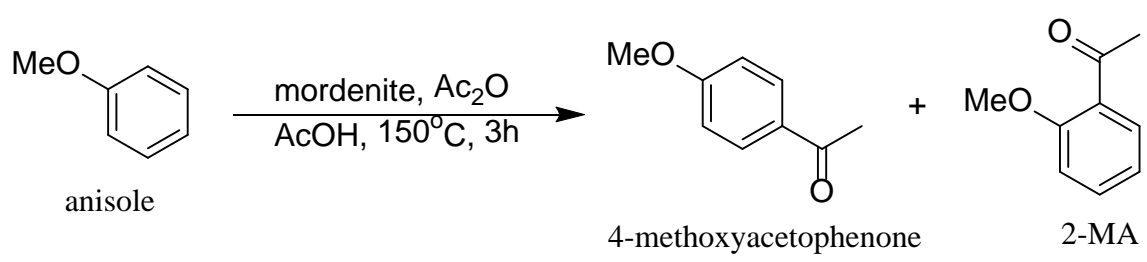
(4-MA)

Figure 1. Friedel-Crafts acylation of anisole by mordenite catalyst. 
formed using an X-ray Fluorescence Spectroscopy (XRF) (BRUKER S8 TIGER). Nitrogen adsorption and desorption isotherm measurements were carried out on a Belsorp 28SA apparatus (Bel, Japan). Ammonia temperature programmed desorption $\left(\mathrm{NH}_{3}\right.$-TPD) experiments were conducted on a TPD-66 apparatus (Bel Japan): the sample was evacuated at $400^{\circ} \mathrm{C}$ for $1 \mathrm{~h}$, and ammonia was adsorbed at $100^{\circ} \mathrm{C}$ followed by further evacuation for $1 \mathrm{~h}$. Then, the sample was heated from $100^{\circ} \mathrm{C}$ to $710^{\circ} \mathrm{C}$ at the rate of $10^{\circ} \mathrm{C} / \mathrm{min}$ in a helium stream. Solidstate ${ }^{29} \mathrm{Si}$ magic angle spinning (MAS) NMR spectra, and ${ }^{27} \mathrm{Al}$ MAS NMR spectra were recorded at ambient temperature by using $4 \mathrm{~mm}$ diameter zirconia rotor with a spinning rate of $6 \mathrm{kHz}$ (ECA-500 NMR spectrometer, JEOL Ltd.). Due to ratios of $\mathrm{SiO}_{2} / \mathrm{Al}_{2} \mathrm{O}_{3}$ in $\mathrm{MOR}(200)$ is almost the limit of measurement, thus MOR(200) was adsorpted by $\mathrm{NH}_{3}$ using aqueous ammonium for enhancement of the intensity. Thermal gravimetric (TGA) and differential thermal (DTA) analyses were carried out by using a Shimadzu DTG-50 analyser at a ramping rate of $10^{\circ} \mathrm{C} / \mathrm{min}$ under an air stream. The crystal size and morphology were measured by field emission scanning electron microscopy (FE-SEM) (S-4800; Hitachi High-Technologies Co., Japan). The products were analyzed by a Shimadzu Gas Chromatograph GC-18 with FID (Column: Ultra-1 capillary column; Agilent Technologies, CA, USA).

MOR-type zeolites were gifted from Tohsoh and used after calcination at $500^{\circ} \mathrm{C}$ for $5 \mathrm{~h}$ under air flow. Whereas organic reagents such as anisole, acetic anhydride and acetic acid were purchased from Tokyo Chemical Industry, Co., LTD. and used without any purification.

\subsection{Reaction}

The typical reaction procedure; the prescribed amount of anisole $(2.0 \mathrm{mmol})$, an acetylating agent (acetic anhydride, $20 \mathrm{mmol}$ ) and zeolite catalyst $(0.50 \mathrm{~g})$ were dissolved in $\mathrm{AcOH}(5 \mathrm{~mL})$, then the resulting mixture was stirred at $150^{\circ} \mathrm{C}$. The product yield and selectivity of the isomers were estimated by GC compared with authentic samples. It is note that, in the conditions, there is no formation of $\mathrm{Ac}_{2} \mathrm{O}$ from $\mathrm{AcOH}$.

\subsection{Reaction}

After the reaction, the mordenite catalyst was recovered by filtration and washed with EtOAc (ca. $20 \mathrm{~mL}$ ). Resulting zeolite was calcined at $500^{\circ} \mathrm{C}$ for $5 \mathrm{~h}$ under air flow, and then re-used as the catalyst for next reaction described above.

\section{Results and Discussion}

Figure 2 shows the reaction profiles of Friedel-Crafts acylation of anisole by $\operatorname{MOR}(200)$ and MOR(110) catalysts, respectively. The reactions were carried out using $\mathrm{Ac}_{2} \mathrm{O}$ in $\mathrm{AcOH}$ at $150^{\circ} \mathrm{C}$. Amazingly, although the acylation of 2-MN by MOR(200) catalyst takes for $48 \mathrm{~h}$ to accomplish the reaction, the acetylation of anisole rapidly occurred within $3 \mathrm{~h}$ in $>99 \%$ conversion and the selectivity of 4 -MA was detected in $>99 \%$ in the presence of low acid amount of zeolite cata- 



Figure 2. Pore structure of mordenite zeolite [001] and [100] directions (left). Reaction profiles of Friedel-Crafts acylation of anisole over MOR(200) (blue circle) and MOR(110) (red square) (right).

lyst MOR(200). Further, in this reaction system, MOR(110) zeolite also showed the excellent catalytic performance; $>99 \%$ conversion of anisole and $>99 \%$ selectivity of 4-MA only for $2 \mathrm{~h}$, respectively. These results obviously indicate that the reaction proceeds by high shape selective manner of mordenite zeolite catalysts, because mordenite has a straight pore channel composed by 12-membered ring along with [001] direction in Figure 2(left) [19], thus it allows not only facile formation of the slimmest isomer (4-MA) but also to diffuse out smoothly rather than those of 2,6-ACMN. However the usage of higher acidity MOR(30) catalyst gave moderate conversion in $63 \%$, albeit $4-\mathrm{MA}$ in $>99 \%$ selectivity. These results suggest that this reaction system does not need a high Brønsted acidity, but the reaction never occurs in the absence of mordenite catalyst.

Other substrates for producing key intermediates were also examined in this reaction system. For examples, utilizing isobutylbenzene affording an ibuprofen intermediate gave low yield in 9\%, albeit quantitative para-selectivity. The reaction of 4-methoxybiphenyl gave unsatisfactory low yield in $27 \%$ with quantitative selectivity of 4'-acetyl-4-methoxybiphenyl in Figure 3. Davis et al. also claimed the low conversion of isobutylbenzene over BEA zeolite and the effect of external surface contributed significantly, not by shape selective manner of zeolite pore [20].

The experiment of reusability and recyclability of $\operatorname{MOR}(200)$ zeolite using anisole and $\mathrm{Ac}_{2} \mathrm{O}$ in $\mathrm{AcOH}$ (Figure 4(left)) gave the amazing result, showing the quantitative conversions of anisole and the selectivities of $4-\mathrm{MA}$ in $>99 \%$ in 30 times reactions. Obviously this result must be intriguing catalytic performance of MOR(200) zeolite for acylation of anisole leading to 4-MA. Figure 4(right) gives the powder-XRD charts of fresh (a) and after 30 times used MOR(200) zeolites (b), respectively. Even many times used, there was no observable for significant different peak patterns in both samples, suggesting that three-dimensional structure of MOR(200) zeolite (the topology of MOR and its framework 


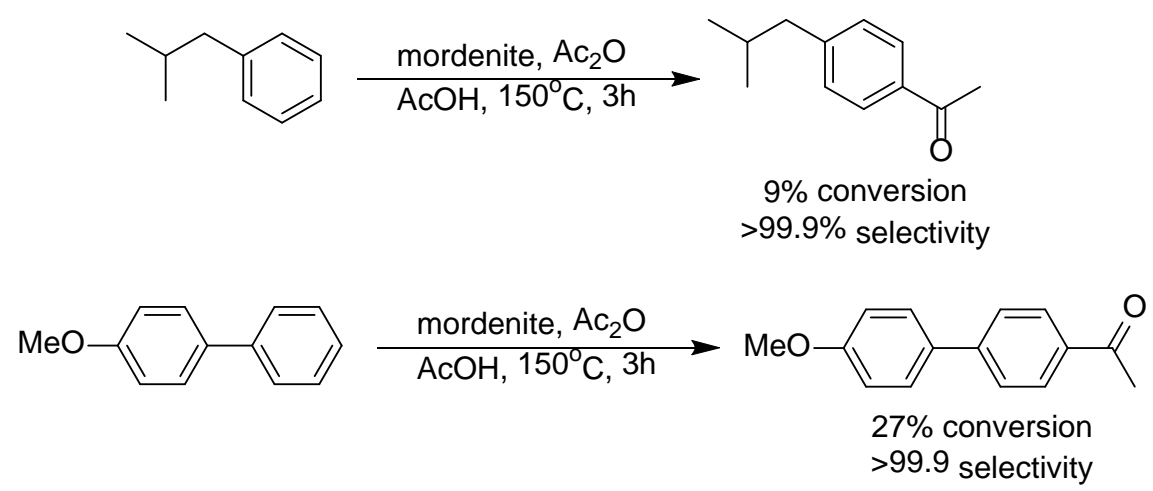

Figure 3. Mordenite zeolite catalyzed Friedel-Crafts acylation of isobutylbenzene (up) and 4-methoxybiphenyl (down).
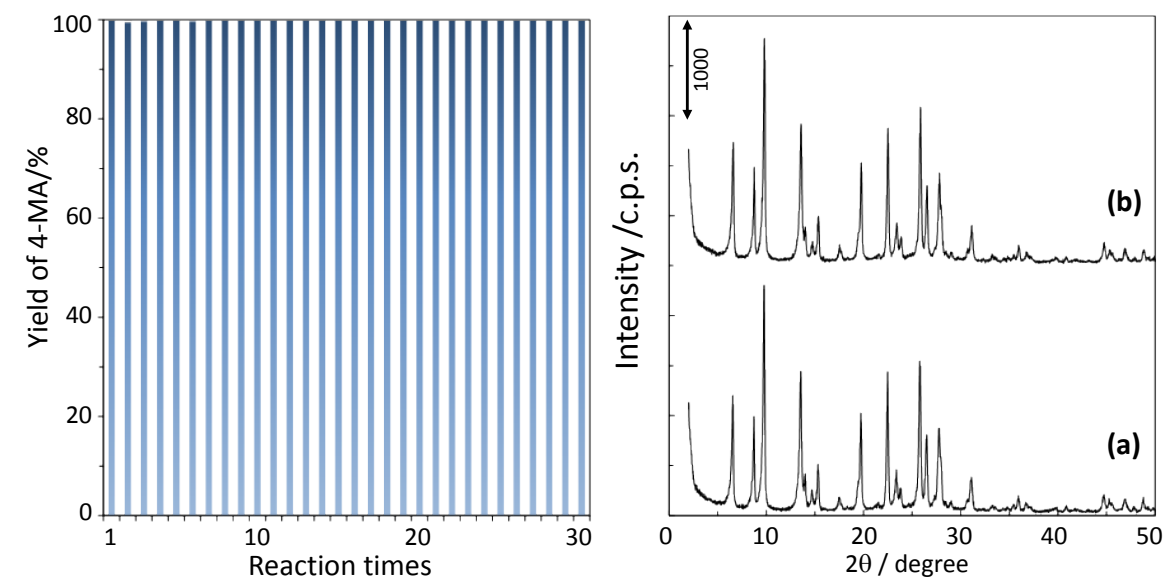

Figure 4. The results of reusability by $\operatorname{MOR}(200)$ in Friedel-Crafts acylation of anisole (left) and powder-XRD charts of fresh (a) and after 30 times used MOR(200) (b) zeolite catalysts (right).

structure) was found to be robust enough. Table 1 gives the textural parameters of the MOR zeolite catalysts. Regardless of decreasing surface area of the used mordenite, the considerable changes of the ratio of $\mathrm{SiO}_{2} / \mathrm{Al}_{2} \mathrm{O}_{3}$, pore volume and acidity could not be detectable; suggesting that, in practical mind, the mordenite zeolite must be the excellent catalyst in this reaction system for producing 4-MA due to its quantitative conversion, the selectivity, the reusability and the recyclability.

Figure 5 gives the FE-SEM images (left), ${ }^{29}$ Si MAS NMR spectra (middle) and ${ }^{27} \mathrm{Al}$ MAS NMR spectra of $\mathrm{NH}_{3}$-adsorpted mordenite catalysts (right). FE-SEM measurements of fresh (a) and the used zeolite catalysts (b) revealed that the crystal of the used mordenite became rugged surface and smaller particle size. However the amorphous phase and significant collapse of its morphology was negligible in the measurement, reflecting no considerable difference of XRD peaks in Figure 4.

${ }^{29} \mathrm{Si}$ MAS NMR spectra of both samples; fresh (a) and the used zeolite (b), were not determined a considerable difference. This result indicates that there is no amorphous silica formation from leaching $\mathrm{Si}$ atom during the reaction. How- 


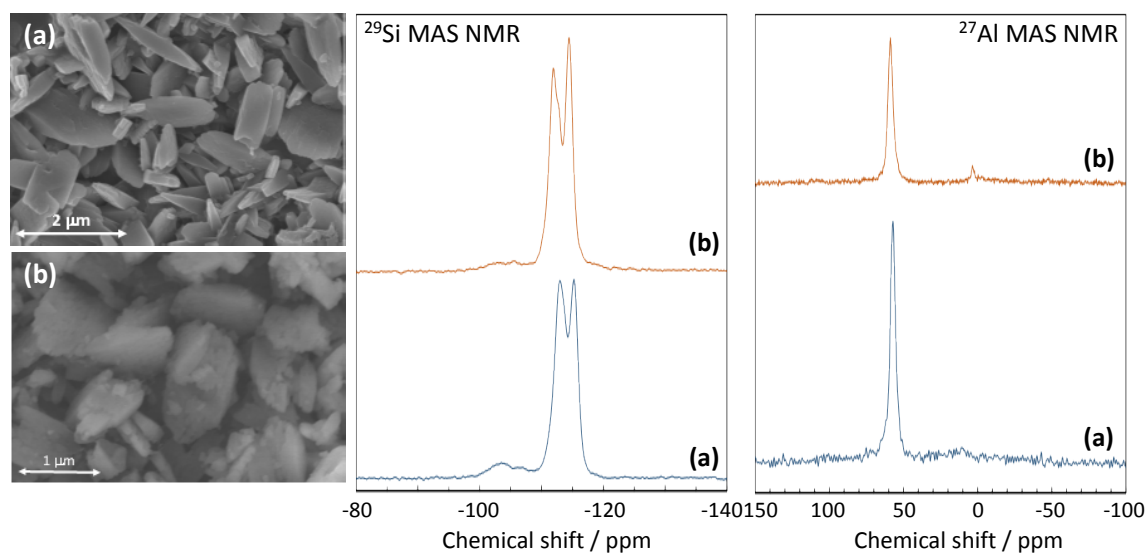

Figure 5. FE-SEM images, ${ }^{29}$ Si magic-angle-spinning (MAS) NMR spectra and ${ }^{27} \mathrm{Al}$ MAS NMR spectra of fresh MOR(200) (a) and after used mordenite catalyst (b).

Table 1. Textural parameters of mordenite catalysts.

\begin{tabular}{ccccc}
\hline Entry & $\mathrm{SiO}_{2} / \mathrm{Al}_{2} \mathrm{O}_{3}{ }^{\mathrm{a}}$ & Surface $\mathrm{area}^{\mathrm{b}} / \mathrm{m}^{2} \cdot \mathrm{g}^{-1}$ & Pore volume $/ \mathrm{mL} \cdot \mathrm{g}^{-1}$ & Acid amount $^{\mathrm{d}} / \mathrm{mmol} \cdot \mathrm{g}^{-1}$ \\
\hline $1^{\mathrm{e}}$ & 200 & 520 & 0.27 & 0.041 \\
$2^{\mathrm{e}}$ & 106 & 579 & 0.35 & 0.051 \\
$3^{\mathrm{f}}$ & 195 & 470 & 0.28 & 0.036 \\
\hline
\end{tabular}

${ }^{\mathrm{a}}$ Estimated by XRF, ${ }^{\mathrm{b}} \mathrm{BET}$ surface area, ${ }^{\mathrm{C}}$ Estimated from nitrogen adsorption isotherm, ${ }^{\mathrm{d}}$ Measured by $\mathrm{NH}_{3}$ TPD, ${ }^{e}$ Fresh mordenite, ${ }^{\mathrm{f}}$ After 30 times used mordenite.

ever, in ${ }^{27} \mathrm{Al}$ MAS NMR spectra of $\mathrm{NH}_{3}$-adsorpted mordenite catalysts (right), it can be observed the octahedral $\mathrm{Al}$ atom at $0 \mathrm{ppm}$ which is mainly attributed to existence of $\mathrm{Al}_{2} \mathrm{O}_{3}$ after the used zeolite (b) in Figure 5(right). This indicates the leaching of $\mathrm{Al}$ atom locating at the acid site by the repetitive reactions, because the spectrum of the fresh $\operatorname{MOR}(200)$ (a) is not observable at 0 ppm and only tetrahedral framework of $\mathrm{Al}$ atom is detected at $57 \mathrm{ppm}$. In order to enhance the intensity of $\mathrm{Al}$ atom using $\mathrm{NH}_{3}$ as a probe molecule, although the quantitative assign cannot be possible, it can be implied that the peak intensity of octahedral $\mathrm{Al}$ atom was very small comparing with that of tetrahedral $\mathrm{Al}$ atom. According to the results of XRD, NMR and textural parameters given in Table 1, it can be presumed that almost $\mathrm{Al}$ atom should be retained at mordenite framework after 30 times reactions having enough acidity for catalysis.

\section{Conclusion}

Friedel-Crafts acylation of anisole was studied using $\mathrm{Ac}_{2} \mathrm{O}$ and mordenite catalyst in $\mathrm{AcOH}$. Interestingly, the low acid amount of mordenite zeolite with $\mathrm{SiO}_{2} / \mathrm{Al}_{2} \mathrm{O}_{3}=200$ (MOR(200)) showed quantitative conversion in $>99 \%$ for $3 \mathrm{~h}$ and the selectivity of $4-\mathrm{MA}$ in $>99 \%$. Further it was also found that the MOR (100) catalyst showed quantitative conversion within $2 \mathrm{~h}$ with $>99 \%$ selectivity of 4-MA. Unexpectedly, the higher acid amount of MOR(30) gave moderate conversion in $63 \%$ with $>99 \%$ selectivity. Amazingly, the experiment of reusability and recyclability of $\operatorname{MOR}(200)$ zeolite catalyst gave the excellent results; there is 
no declination of the catalytic activity and the quantitative selectivity in 30 times reactions of anisole in our reaction system. Based upon characterizations of fresh and the used mordenite zeolites, it presumptively revealed that almost $\mathrm{Al}$ atom at Brønsted acid site of mordenite catalyst is hard to leach out from its robust framework structure, therefore the catalytic performances (conversion and shape selectivity) do retain in the repetitive reactions. This distinctive opportunity must be intriguing and offers a novel green synthetic tool by heterogeneous Friedel-Crafts acylation of anisole. The further researches are ongoing in our laboratory.

\section{Acknowledgements}

K.K. thanks for this work supported by JSPS KAKENHI Grant Number 15K05586.

\section{References}

[1] Climent, M.J., Corma, A. and Iborra, S. (2010) Zeolite as Catalysts for the Synthesis of Fine Chemicals. In: Čejka, J., Corma, A. and Zones, S., Eds., Zeolites and Catalysis, Wiley-VCH, Weinheim, 775-783. https://doi.org/10.1002/9783527630295.ch25

[2] Bejblová, M., Procházková, D. and Čejka, J. (2009) Acylation Reactions over Zeolite and Mesoporous Catalysts. ChemSusChem, 2, 486-499.

https://doi.org/10.1002/cssc.200900007

[3] Derouane, E.G., Dillon, C.J., Bethell, D. and Derouane-Abd Hamid, S.B. (1999) Zeolite Catalysts as Solid Solvents in Fine Chemicals Synthesis. Journal of Catalysis, 187, 209-218. https://doi.org/10.1006/jcat.1999.2575

[4] Freese, U., Heinrich, F. and Roessner, F. (1999) Acylation of Aromatic Compounds on H-BEA Zeolites. Catalysis Today, 49, 237-244. https://doi.org/10.1016/S0920-5861(98)00429-5

[5] Ji, X., Qin, Z., Dong, M., Wang, G., Dou, T. and Wang, J. (2007) Friedel-Crafts Acylation of Anisole and Toluene with Acetic Anhydride over Nano-Sized Beta Zeolites. Catalysis Letters, 117, 171-176. https://doi.org/10.1007/s10562-007-9131-8

[6] Smith, K., Zhenhua, Z. and Hodgson, P.K.G. (1998) Synthesis of Aromatic Ketones by Acylation of Aryl Ether with Carboxylic Anhydrides in the Presence of Zeolite $\mathrm{H}-(\mathrm{H}-\mathrm{BEA})$ in the Absence of Solvent. Journal of Molecular Catalysis A: Chemical, 134, 121-128. https://doi.org/10.1016/S1381-1169(98)00028-4

[7] Rohan, D., Canaff, C., Fromentin, E. and Guisnet, M. (1998) Acetylation of Anisole by Acetic Anhydride over a HBEA Zeolite-Origin of Deactivation of the Catalyst. Journal of Catalysis, 177, 296-305. https://doi.org/10.1006/jcat.1998.2108

[8] Kantam, M.L., Ranganath, K.V.S., Sateesh, M., Kumar, K.B.S. and Choudary, B.M. (2005) Friedel-Crafts Acylation of Aromatics and Heteroaromatics by Beta Zeolite. Journal of Molecular Catalysis A: Chemical, 225, 15-20. https://doi.org/10.1016/j.molcata.2004.08.018

[9] Zhao, D., Wang, J. and Zhang, J. (2008) Effect of Modified Beta Zeolites with Acid on Anisole Acetylation in a Fixed Bed Reactor. Catalysis Letters, 126, 188-192. https://doi.org/10.1007/s10562-008-9605-3

[10] Guidotti, M., Coustard, J.-M., Magnoux, P. and Guisnet, M. (2007) Acetylation of Aromatics over Acid Zeolites: Seeking a Viable Alternative to Friedel-Crafts Catalysts. Pure and Applied Chemistry, 79, 1833-1838. https://doi.org/10.1351/pac200779111833

[11] Selvin, R., Hsu, H.-L. and Her, T.-M. (2008) Acylation of Anisole with Acetic An- 
hydride Using ZSM-5 Catalysts: Effect of ZSM-5 Particle Size in the Nanoscale Range. Catalysis Communications, 10, 169-172. https://doi.org/10.1016/j.catcom.2008.08.013

[12] Gaare, K. and Akproriaye, D. (1996) Modified Zeolites as Catalysts in the Friedel-Crafts Acylation. Journal of Molecular Catalysis A: Chemical, 109, 177-187. https://doi.org/10.1016/1381-1169(96)00023-4

[13] Bond, G., Gardner, J.A., McCabe, R.W. and Shorrock, D.J. (2007) Friedel-Crafts Acylation Reactions Using Heterogeneous Catalysts Stimulated by Conventional and Microwave Heating. Journal of Molecular Catalysis A: Chemical, 278, 1-5. https://doi.org/10.1016/j.molcata.2007.07.048

[14] Choudary, B.M., Sateesh, M., Kantam, M.L. and Prasad, K.V.R. (1998) Acylation of Aromatic Ethers with Acid Anhydrides in the Presence of Cation-Exchanged Clays. Applied Catalysis A: General, 171, 155-160. https://doi.org/10.1016/S0926-860X(98)00076-3

[15] Alvaro, M., Corma, A., Das, D., Fornés, V. and García, H. (2005) “Nafion”- Functionalized Mesoporous MCM-41 Silica Shows High Activity and Selectivity for Carboxylic Acid Esterification and Friedel-Crafts Acylation Reactions. Journal of Catalysis, 231, 48-55. https://doi.org/10.1016/j.jcat.2005.01.007

[16] Winé, G., Huu, C.P. and Ledoux, M.J. (2006) Acylation of Anisole by Acetic Anhydride Catalyzed by BETA Zeolite Supported on Pre-Shaped Silicon Carbide. Catalysis Communications, 7, 768-772. https://doi.org/10.1016/j.catcom.2006.03.002

[17] Sarsani, V.S.R., Lyon, C.J., Hutchenson, K.W., Harmer, M.A. and Subramaniam, B. (2007) Continuous Acylation of Anisole by Acetic Anhydride in Mesoporous Solid Acid Catalysts: Reaction Media Effects on Catalyst Deactivation. Journal of Catalysis, 245, 184-190. https://doi.org/10.1016/j.jcat.2006.10.001

[18] Yamazaki, T., Makihara, M. and Komura, K. (2017) Zeolite Catalyzed Highly Selective Synthesis of 2-Methoxy-6-Acetylnaphthalene by Friedel-Crafts Acylation of 2-Methoxynaphthalene in Acetic Acid Reaction Media. Journal of Molecular Catalysis A: Chemical, 426, 170-176. https://doi.org/10.1016/j.molcata.2016.11.012

[19] Database of Zeolite Structures at Homepage in International Zeolite Association. http://asia.iza-structure.org/IZA-SC/ftc_table.php

[20] Andy, P., Martinez, J.G., Lee, G., Gonzalez, H., Jones, C.W. and Davis, M.E. (2000) Acylation of 2-Mthoxynaphthalene and Isobutylbenzene over Zeolite Beta. Journal of Catalysis, 192, 215-223. https://doi.org/10.1006/jcat.2000.2855

Scientific Research Publishing

Submit or recommend next manuscript to SCIRP and we will provide best service for you:

Accepting pre-submission inquiries through Email, Facebook, LinkedIn, Twitter, etc. A wide selection of journals (inclusive of 9 subjects, more than 200 journals)

Providing 24-hour high-quality service

User-friendly online submission system

Fair and swift peer-review system

Efficient typesetting and proofreading procedure

Display of the result of downloads and visits, as well as the number of cited articles

Maximum dissemination of your research work

Submit your manuscript at: http://papersubmission.scirp.org/

Orcontact gsc@scirp.org 